\title{
PEMENUHAN GIZI KELUARGA DAN TAMBAHAN PENGHASILAN RUMAH TANGGA MELALUI OPTIMALISASI PEKARANGAN RUMAH DI KELURAHAN KUIN UTARA
}

\author{
Andi Suci Anita, Edward Zubir, dan Mukhyar Amani \\ Fakultas Matematika dan Ilmu Pengetahuan Alam, Universitas Terbuka \\ Email :andisuci@ecampus.ut.ac.id
}

\begin{abstract}
ABSTRACK
One of the new strategies in increasing food consumption is through the use of yard land. The yard is a plot of land around the house that can be used for the purpose of improving the nutrition of the micro through the improvement of the family menu. In terms of land use, yard is an effort to optimize the use of land because it can be carried out various agricultural activities of high value. However the narrowness of the home yard, if managed properly will produce something of high value. By planting vegetables in your own yard, it is hoped to be one of the best savings solutions by not reducing the nutritional needs of family members.

Partners Devotion to the community are housewives housed in the alley Palapa RT. 5 KelurahanKuin Utara North Banjarmasin with a source of household income from fish cracker making business, shrimp crackers, factory workers, carpenters, masons, massage services, selling stalls and fried foods. The location of this service is close to the river basin so it looks shabby and according to the local government of Kuin Utara Village, that the majority of society's income is uncertain every month, then supported by the condition of the yard is still possible to plant so it is suitable to do the PkM UT in this environment.

Methods performed on community service are carried out by giving counseling about home garden optimization, vegetable seed distribution, planting medium and shelf arrangement, mentoring and monitoring (evaluation).

The purpose of this activity is to optimize the home yard as a source of nutrition of family members and increase household income and increase the knowledge of the community in using the narrow yard with organic vegetables cultivation free of pesticides.
\end{abstract}

\section{Keywords : Incremental Income, Optimal Home Yard, Planting Vegetables}

\section{PENDAHULUAN}

Salah satu strategi baru dalam

meningkatkan konsumsi pangan adalah

melalui pemanfaatan lahan pekarangan.

Pekarangan merupakan sebidang tanah

di sekitar rumah yang dapat

dimanfaatkan dengan tujuan untuk

meningkatkan penemuhan gizi mikro melalui perbaikan menu keluarga. Dari segi pemanfaatan lahan, pekarangan merupakan usaha optimalisasi pemanfaatan lahan karena dapat dilakukan berbagai kegiatan pertanian yang bernilai tinggi. Bagaimanapun sempitnya pekarangan rumah, apabila dikelola dengan baik akan 
menghasilkan sesuatu yang bernilai tinggi.

Lahan pekarangan rumah yang relatif sempit memiliki peran yang sangat kompleks sehingga pemanfaatannya harus direncanakan sedemikian rupa agar dapat berfungsi optimal, baik dalam hal tingkat produksi maupun dalam pemanfaatan lainnya dengan melihat keindahan penataan. Strategi yang dapat diambil untuk budidaya sayur yaitu dengan menggunakan model yang mudah dipindahkan dengan memanfaatkan pot, polybag, talang air atau pipa paralon yang disusun sedemikian rupa.

Bertanam sayur di pekarangan memiliki banyak kelebihan. Selain bisa memenuhi kebutuhan keluarga, pekarangan pun tampak asri jika ditata dengan baik. Misalnya, pot tanaman terung atau daun yang disusun sedemikian rupa sehingga tampak indah dipandang mata. Kelebihan lain dengan bertanam sayur di pekarangan rumah adalah sayuran yang dipetik lebih segar dan lebih sehat. Bahkan, sayuran tersebut bisa dibuat organik (Paeru dan Trias, 2015)

Berdasarkan analisis situasi tersebut, salah satu solusi untuk mengatasi hal tersebut adalah dengan bertanam sayuran di pekarangan rumah sendiri. Kegiatan ini diharapkan dapat menjadi salah satu solusi penghematan yang baik dengan tidak mengurangi kebutuhan gizi anggota keluarga untuk mendapatkan kebutuhan sayuran yang murah dan segar serta jika hasil berlebih dapat dijual sebagai sumber pendapatan sampingan atau tambahan.

Tujuan dilaksanakan kegiatan PkM adalah (1). Mengoptimalkan fungsi pekarangan rumah; (2) Meningkatkan pemenuhan gizi anggota keluarga; (3) Menambah penghasilan rumah tangga; dan (4) Meningkatkan pengetahuan masyarakat dalam memanfaatkan pekarangan sempit dengan budidaya sayuran secara organik bebas pestisida.

\section{KHALAYAK SASARAN}

Mitra Pengabdian kepada masyarakat adalah ibu-ibu rumah tangga dengan sumber penghasilan rumah tangga dari usaha pembuatan kerupuk ikan, kerupuk udang, buruh pabrik, tukang kayu, tukang batu, jasa pijat/urut, jualan warung dan gorengan. Dengan penghasilan rumah tangga yang tidak memadai ditambah lagi dengan meningkatnya harga bahan pokok termasuk sayuran sehingga ibu-ibu rumah tangga dengan terpaksa 
melakukan penghematan dengan menekan berbagai keperluan rumah tangga termasuk sayuran, yang penting bisa beli beras, ikan, bumbu dapur dan lombok.

\section{METODE}

Dalam memperoleh hasil yang baik, kegiatan pengabdian masyakarat ini perlu perencanaan yang baik dan matang. Kegiatan ini diawali dengan melakukan penyuluhan, penerapan langsung ke mitra PkM, pendampingan, evaluasi kegiatan, pelaporan monitoring.

\begin{tabular}{|l|l|}
\hline No & \multicolumn{1}{|c|}{ Uraian Kegiatan } \\
\hline 1. & $\begin{array}{l}\text { Mengkoordinir Pelaksanaan } \\
\text { Kegiatan PkM UT dengan } \\
\text { Mitra }\end{array}$ \\
\hline 2. & Penyuluhan \\
\hline & $\begin{array}{l}\text { Materi 1 : Optimalisasi Lahan } \\
\text { Materi 2 : Teknik Bertanam } \\
\text { Sayuran } \\
\text { Materi 3 : Manfaat Sayuran }\end{array}$ \\
\hline 3 & $\begin{array}{l}\text { Penyaluran Bantuan benih } \\
\text { sayuran, media tanam dan rak } \\
\text { susun }\end{array}$ \\
\hline 4 & Pendampingan \\
\hline 5 & Pelaporan \\
\hline 6 & Monitoring \\
\hline
\end{tabular}

\section{HASIL DAN PEMBAHASAN}

\section{Penyuluhan}

Mitra Pengabdian sangat antusias dengan Program Pengabdian kepada Masyarakat yang dilaksanakan oleh Universitas Terbuka. Setelah melakukan
Survey lokasi dan Need Assessment sehingga mengetahui harapan ibu-ibu rumah tangga yang berlokasi di Kelurahan Kuin Utara RT 4 dan 5, Tim kemudian melaporkan akan mengadakan kegiatan di Kantor Kelurahan Kuin Utara, yang sebelumnya tim sudah bersilaturrahim dengan Lurah untuk menunjukkan Kawasan yang dapat dijadikan Target Lokas Pengabdian.

Beberapa kegiatan yang akan dilaksanakann pada Program Pengabdian kepada Masyarakat ini adalah (1). Memberikan Penyuluhan mengenai Optimalisasi Pekarangan Rumah, Tekhnik Bertanam Sayur, dan Manfaat Sayuran. (2) Pemberian polybag, benih sayuran, bibit tanaman yang sudah disemai, media tanam siap pakai, rak susun, pupuk cair dan jetspray. (3) Pendampingan dalam tekhnik penanaman, dan (4) Monitoring pemeliharaan tanaman.

\section{Pekarangan Rumah}

Pekarangan adalah tanah-tanah yang ada disekitar rumah baik yang berada di sebelah kiri dan kanan maupun yang berada di sebelah depan dan belakang yang mempunyai batas-batas hukum yang jelas. Pemanfaatan lahan pekarangan penting dilakukan, karena 
pekarangan merupakan tempat yang terdekat dengan kita, sehingga semua anggota keluarga dapat membantu mengelola lahan pekarang agar dapat menghasilkan berbagai bahan pangan yang bergizi, seperti sayu, buah, dan obat-obatan ( Tim Agro Media, 2006 ). Halaman sempit bukan alasan untuk tidak bisa berkebun, sebab pada prinsipnya budidaya tanaman itu bisa dilakukan di mana saja asalkan ada cahaya dan sirkulasi udara yang optimal. Tidak hanya di halaman sempit, di rumah yang tidak punya halaman sama sekali seperti di rumah susunpun hal itu bisa dilakukan ( Maharanto, 2005 ).

\section{Jenis Sayuran Organik}

Menanam sayuran organik di pekarangan rumah sendiri dapat menjamin kesehatan seluruh anggota keluarga. Beberapa sayuran organik yang mudah ditanam pada polybag adalah :Cabai (Capsicum sp.), Tomat (Solanum Iycopersicum), Terung (Solanum melongena), Caisin (Brassica campestris L-Spp), Pakcoy (Brassica chinensis), Bayam (Amaranthus sp), Kangkung (Ipomea sp.), Seledri (Apium Graveolens)

\section{Media Tanam}

Media tanam yang dipakai sangat mempengaruhi keberhasilan anda dalam menanam sayuran organik. Tanah yang digunakan adalah tanah organik yang subur dan belum tercemar bahan-bahan kimia. Pupuk yang digunakan juga pupuk organik seperti pupuk kompos dan pupuk kandang. Untuk membuat meedia tanam, campurkan tanah dan pupuk organik secara merata dengan perbandingan 1:1. Media tanam ini lantas bisa dimasukkan ke pot/polibag.

\section{Penanaman}

Banih berupa biji ditanamkan ke media tanam dengan kedalaman antara 3-5 $\mathrm{cm}$. Khusus untuk tanaman berbuah seperti tomat dan terong, sebelum ditanam sebaiknya disemai terlebih dahulu agar pertumbuhannya lebih optimal. Sedangkan sayuran berdaun dan sayuran rambat tidak perlu melewati proses penyemaian ini (Zaenal Abidin, 2015)

\section{Pemeliharaan}

Bentuk perawatan sayuran organik berupa penyiraman secara teratur dan pemupukan ulang. Tanaman budidaya idealnya harus disiram setiap dua kali sehari saat pagi dan sore. Sedangkan, pemupukan ulang bisa disesuaikan 
dengan jenis sayuran-sayuran yang dipelihara tersebut. Berikan pupuk majemuk yang mengandung fosfor untuk sayuran berbuah dan berikan pupuk urea untuk sayuran berdaun (Zaenal Abidin, 2015)

Pengendalian hama penyakit lebih mudah dilakukan dalam kegiatan pemanfaatan pekarangan dengan tanaman sayur ini. Untuk tanaman di pot kemungkinan penularan penyakit melalui akar jarang terjadi karena akar diabatasi oleh pot. Pada lahan pekarangan yang sempit kita bisa mengendalikan hama dan penyakit secara manual sehingga penggunaan bahan kimia dapat dibatasi. Hal ini akan membuat sayuran yang dihasilkan dari pekarangan lebih sehat untuk dikonsumsi, karena merupakan sayuran organik (Prapanca, 2005).

Pemberian benih, Media Tanam, dan Rak Susun kepada Mitra PkM

Pada kegiatan Penyuluhan cara mengoptimalkan Pekarangan Rumah, Mitra kegiatan Pengabdian kepada Masyarakat UT langsung diberikan benih sayuran yang siap disemai atau langsung ditanam, media tanam yang berupa tanah organik dan polybag, rak susun tempat penyusunan polybag agar kellihatan indah dan rapih.

\section{Pendampingan}

Tim Kegiatan Pengabdian kepada Masyarakat UT melakukan pendampingan kepada mitra mulai pada proses penyiapan pekarangan, media tanam dan penanaman, penataan polybag sampai pada panen hasil.

Diharapkan dengan pendampingan ini, mitra lebih mengenal potensi pekarangan rumah, teknik bertanam hingga pemeliharaan tanaman. Sehingga, mitra dapat memperoleh hasil panen yang sehat, segar dan higienis.

\section{Partisipasi Mitra}

Mitra yang akan mendapatkan bantuan benih, media tanam dan rak susun polybag adalah warga atau ibu-ibu rumah tangga pada Gang Palapa Kelurahan Kuin Utara Banjarmasin Utara. Pada PkM ini, partisipasi mitra untuk hadir pada penyuluhan Optimalisasi Pekarangan Rumah dengan teknik bertanam Sayuran. Mitra kemudian mempersiapkan pekarangan rumah untuk menata tempat penyusunan polybag secara vertikultur agar terlihat indah dan asri. Mengenai vertikultur, mitra mendapatkan rak susun dari bahan kayu ulin yang telah disiapkan disesuaikan dengan ukuran tempat yang disediakan di pekarangan. Media tanam yang masih berada dalam karung 
disiapkan dalam polybag dan melakukan penanaman bagi benih siap tanam, dan menyemai benih.

\section{FOTO KEGIATAN}
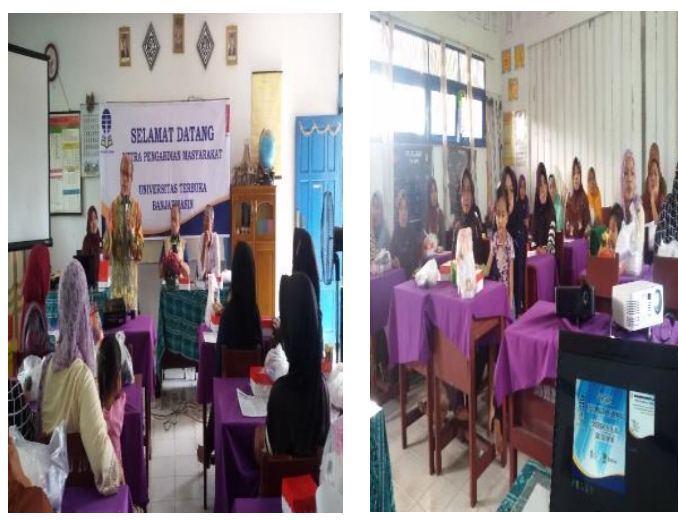

Pelaksanaan Penyuluhan (kiri) dan Mitra PkM Ibu-Ibu RT 4 dan 5 Kelurahan Kuin Utara (kanan)

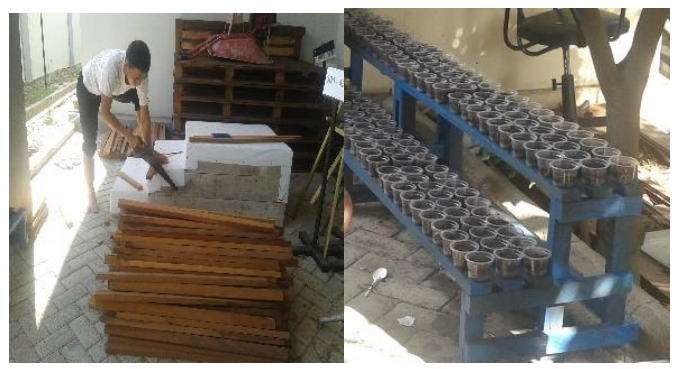

Pembuatan Rak Susun oleh Tim
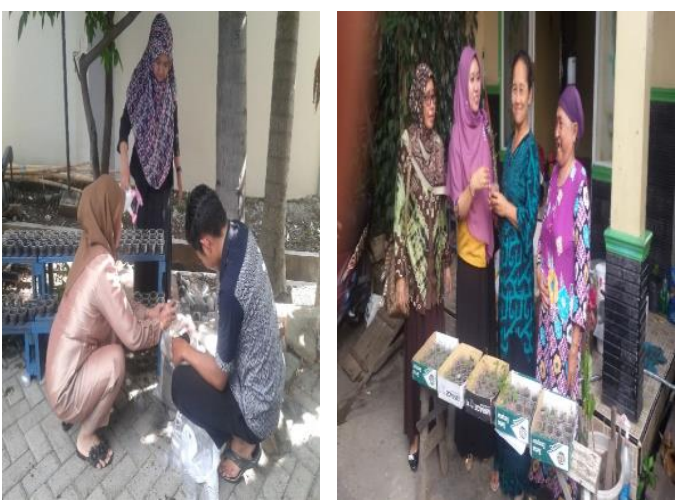

Penanaman benih sayuran (kiri) dan

Penyerahan benih, bibit, dan rak susun ke Mitra PkM (kanan)
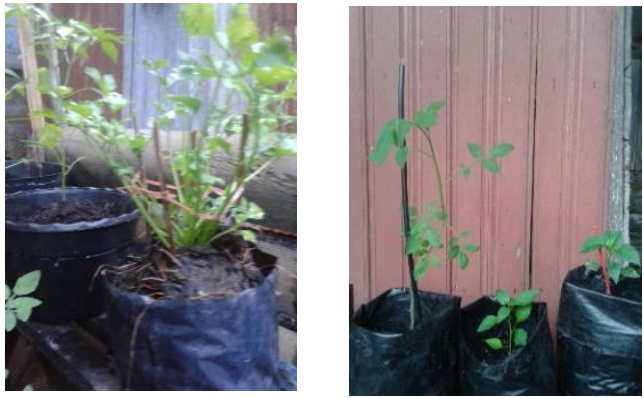

Hasil monitoring PkM pada salah satu mitra setelah 2 bulan pelaksanaan PkM

\section{KESIMPULAN DAN SARAN}

\section{Kesimpulan}

Mitra Kegiatan Pengabdian kepada Masyarakat sangat antusias mengikuti program PkM ini, terlihat dengan adanya upaya mengikuti penyuluhan, penyiangan, penanaman dan pemeliharaan tanaman sayur dalam optimalisasi pekarangan rumah. Selain untuk pemenuhan gizi keluarga, penambahan ilmu pengetahuan, juga sebagai sumber penghasilan tambahan jika hasil berlebih.

\section{Saran}

Mitra Kegiatan Pengabdian Kepada Masyarakat mengharapkan agar program ini dapat dilanjutkan dengan adanya penambahan tanaman lain seperti tanaman obat keluarga (TOGA) yang juga banyak berguna sebagai bumbu dapur. 
DAFTAR PUSTAKA

Badan Ketahanan Pangan Daerah Provinsi Jawa Barat, 2015.Kontribusi Sayuran dalam Pola Pangan Harapan Keluarga Indonesia, http://bkpd.jabarprov.go.id/kontribus i-sayuran-dalam-pola-panganharapan-keluarga-indonesia/, diakses tanggal 2 Maret 2016.

BPTP Sulawesi Selatan, 2012. Budidaya Sayuran di Lahan Pekarangan.

http://sulsel.litbang.pertanian.go.id/in d/index.php?option=com_content \&vi ew=article\&id=802:-budidayasayuran-di-lahan-pekarangan-tahunterbit-2012, diakses tanggal 2 Maret 2016.

Maharanto, 2005. Sayuran Pot di Negara 4 Musim. Trubus Edisi
September No.286. Tahun XXIV.2000. hal 4-6.

Paeru, R.H dan Trias Qurnia Dewi, 2015. Panduan Praktis Bertanam Sayuran di Pekarangan. Penebar Swadaya. Jakarta

Tim Agro Media Pusstaka, 2006. Memanfaatkan rumah dan pekarangan( Menanam sayur di pekarangan rumah). Agro Media Pustaka. Jakarta. 112 hal.

Zaenal Abidin, 2015. Tips Bercocok Tanam Sayuran Organik di Lahan Sempit.

http://pakarbudidaya.blogspot.co.id/2 015/05/tips-bercocok-tanam-sayuranorganik-di.html, diakses tanggal 2 Maret 2016. 